\title{
ESCALA DE EQUILIBRIO DE BERG COMO AVALIAÇÃO EM IDOSOS INSTITUCIONALIZADOS NA CIDADE DE ESTEIO
}

Kelly Diana Pereira da Cruz; Ulbra; kelly.diana@rede.ulbra.br

Andriele Ferreira dos Santos; Ulbra; andriele_7@hotmail.com

Caroline Conrado; Ulbra; carolconradop@outlook.com

Andressa Luz Ferreira; Ulbra; andressahatake25@gmail.com

Prof $=$ Dra Lidiane Requia Alli Feldmann; Ulbra; lidiane.feldmann@ulbra.br

\section{RESUMO}

Introdução: $\mathrm{O}$ equilíbrio postural é essencial para o ser humano, e na população idosa é imprescindível ter um bom equilíbrio, pois a probabilidade de ocorrer quedas nessa população é maior. $\mathrm{O}$ envelhecimento é uma realidade em nosso país, induzindo uma série de modificações no sistema biológico, uma redução progressiva das funções fisiológicas da densidade mineral óssea, perda progressiva da massa muscular, fatores esses que interferem no estilo de vida do idoso, pois muitas dessas modificações influenciam na autonomia reduzindo a capacidade funcional. Objetivo: Verificar o equilíbrio postural em idosos Institucionalizados no município de Esteio. Métodos: A amostra foi composta por 16 idosos $\geq 60$ anos, ambos os sexos sendo 8 homens e 7 mulheres, residentes dessa Instituição, para avaliar o equilíbrio utilizou-se a escala de equilíbrio de Berg, optou-se por excluir idosos com fraturas de membros inferiores nos últimos 3 meses e com déficit visual grave.Resultados: A média de idade das mulheres foi de 77,62 e dos homens foi de 78,14 em relação ao teste de equilíbrio de Berg o sexo feminino apresentou a média de escore 38, e do sexo masculino apresentou uma média 45,5. Conclusão: Identificou-se que nas mulheres a pontuação indicou uma locomoção segura, recomendação de assistência ou auxilio de marcha, e nos homens a pontuação indicou que não existiu marcadores de risco de quedas e que possuía uma locomoção segura. $\mathrm{O}$ diretor dessa ILPI informou que a maioria dos idosos que realizam algum tipo de exercício físico três vezes na semana podendo ser um indicativo importante.

Palavras-chave: Equilíbrio Postural; Saúde do Idoso Institucionalizado; Envelhecimento.

\section{Referências}

SANTOS, Gilmar M. et al . Valores preditivos para o risco de queda em idosos praticantes e não praticantes de atividade física por meio do uso da Escala de Equilíbrio de Berg. Rev. bras. fisioter., São Carlos, v. 15, n. 2, p. 95-101, Apr. 2011 .

ARAUJO NETO, Antonio Herculano de et al . Quedas em idosos institucionalizados: riscos, consequências e antecedentes. Rev. Bras. Enferm., Brasília, v. 70, n. 4, p. 719-725, Aug. 2017. 